\title{
On the Cyclicality and Stability of Real Earnings
}

\author{
ROBERT A HART
}

JAMES R MALLEY

April, 1999

\begin{abstract}
:
We show in this paper that important insights into the cyclical behaviour of wages can be gained by dividing (real) average hourly earnings into their straight-time hourly wage and overtime components. Our motivation is based on the idea of employment-contingent contracts. BLS published and unpublished statistics are used to decompose average earnings into (i) the straight-time wage rate, (ii) the 'mark-up' needed to achieve an overtime worker's earnings rate, and (iii) the proportion of workers working overtime. Using monthly manufacturing data from 1962-1997, cyclicality measures of these components are based on contemporaneous bivariate correlations using four alternative detrending methods while stability is examined using recursive estimation and testing methods. While the wage rate is generally acyclical and unstable, the other two components are highly pro-cyclical and relatively stable.
\end{abstract}

\section{JEL Classification Numbers: J3, J41}

\section{Acknowledgements:}

We thank Christian Dustmann, Ulrich Woitek and seminar participants at the University of Glasgow for helpful comments and suggestions. We would also like to thank John Stinson and Sharon Gibson of the Bureau of Labor Statistics, U.S. Department of Labor for providing us with unpublished data relating to hours of work and consumer prices respectively. Part of this work was undertaken while Bob Hart was visiting the Institute for the Study of Labor (IZA) in Bonn, Germany and this author is grateful for the research facilities provided. 


\section{Introduction}

Wage setting behaviour of workers and management often reflects aims and objectives which do not closely relate to current economic events. For example, where wage contracts cover efficiency criteria or rent sharing agreements we may not observe wage rates that respond flexibly to aggregate shocks. ${ }^{1}$ Models based on these and other objectives have been used to underscore the empirical observation that wage rates are not well correlated with the cycle and do not display cyclical stability. For simplicity, many of the theoretical models treat the wage as a single rate of hourly pay. In reality, worker compensation consists of several wage and non-wage components that are aimed at fulfilling a range of labour market objectives. Perhaps one of the best researched examples in this respect is the differing roles played by cash earnings and bonuses in Japan. Firms and workers may have compensation agreements in which part of the compensation is largely independent of and part is highly dependent on the amount of labour services requirement. In this event, the cyclical direction and stability of the two parts may behave quite differently. Following this sort of argument, we show in this paper that important insights into the cyclical behaviour of (real) average hourly earnings (the earnings rate) can be gained by dividing it into the straight-time hourly wage (the wage rate) and into its overtime components.

Our motivation relates to the work of Hall and Lilien (1979) on approximately efficient contracts under conditions of uncertain demand and supply. Where demand fluctuations are of more concern to collective bargainers, efficiency is realised if firms are made to internalise workers' opportunity costs by equating marginal labour cost and marginal opportunity cost. Management unilaterally determines employment given high transaction costs of the parties reaching agreement on current information. The compensation rule consists of a fixed cash payment determined by distributional considerations and independent of labour service

\footnotetext{
${ }^{1}$ Blanchard and Fischer (1989) provide a review of some relevant contract models.
} 
requirement and a component that varies directly with labour service. Institutionally, agreement to allow management to change the employment stock is most easily achieved when temporary layoffs are made among a permanent workforce. A rule that links marginal compensation strongly to employment change is a pronounced two-step wage schedule whereby a relatively high overtime premium is enforced above a laid-down hours threshold. Under these circumstances, the wage rate component of the (typically) three year contract may have little to do with current demand but reflect such issues as inter-industry wage differentials. By contrast, the overtime schedule represents part of the employment contingent aspect of the contract. Observing fluctuations in the earnings rate taken as a whole may give a completely misleading picture of the behaviour of these two types of components. We present evidence in this paper that is strongly supportive of this contention.

In Section 2, we provide a simple economic rationale, based on Hall and Lilien's framework, for the need to study the cyclicality of the earnings rate by decomposing it into wage rate and overtime components. Our empirical contribution is two-fold. First, in Section 3, we separate the earnings rate into (a) the wage rate, (b) the 'mark-up', or the weight that attaches to the wage rate of an overtime worker to convert it to the earnings rate and (c) the proportion of workers working overtime. We use aggregate manufacturing Bureau of Labor Statistics (BLS) monthly data from 1962 to 1997, including unpublished statistics, that allow us to identify the three components. Second, in Section 4, we estimate the cyclicality and stability of the components. Our measures of cyclicality are based on contemporaneous bivariate correlations using four alternative methods of removing trend from the data. The issue of stability is examined using recursive estimation and testing methods. In Section 5, we highlight the fact that overtime working may not be the only aspect of workers' total compensation that displays regularities and that other premiums and non-wage benefits may be usefully examined in future work. 


\section{The overtime component of the earnings rate under varying demand conditions}

Given problems of asymmetric information and moral hazard, collective bargainers may establish compensation rules that provide approximately efficient outcomes. Hall and Lilien (1979) observe that (i) collective bargaining agreements are often not contingent on outside events; (ii) employers have large discretionary powers to change employment in the face of unanticipated demand shifts; (iii) wage agreements are negotiated on regular (usually 3-year) cycles; and (iv) current demand has little impact on newly negotiated wage schedules. Approximately efficient employment-contingent contracts have a finite duration, changing over regular cycles, and are designed to maintain efficiency in the face of what is deemed to be the dominant source of large fluctuation. We follow Hall and Lilien by assuming that bargainers are most likely to seek contacts that deal with demand fluctuations since this is the most likely dominant source of inefficiency over the life of a three year contract. In this case, the compensation rule is based on expectations about the opportunity cost of labour and management can adjust employment unilaterally to meet anticipated demand. To achieve efficiency under these circumstances, the marginal rate of compensation must increase with employment in order to reflect increasing marginal opportunity cost. Employment-sensitive marginal compensation is achieved by a mandated overtime payment rule that imposes a high premium for achieving intensive labour utilisation. Since efficiency depends on management's ability to vary employment, pricing overtime in this way allows the achievement of long hours on the intensive margin. On the extensive margin, workers are most likely to give managers discretion over altering the size of the employment stock if this takes the form of short-term layoffs among a permanent workforce.

Against this background, suppose that the wage schedule in a given firm has been set for the period ahead, with the straight-time wage representing largely distributional characteristics. Management is given discretion to vary the size of the permanent workforce 
during the contract period and also faces an exogenous overtime payments rule with respect to hours variation. The use of overtime schedules to ensure an employment-contingent marginal rate of compensation, necessitates defining labour service in its stock and utilisation dimensions (see, for example, FitzRoy and Hart (1985)).

Let $\mathrm{N}=\mathrm{N}(\theta)$ be the number of workers from a permanent workforce, $\overline{\mathrm{N}}$, employed in demand-state $\theta$ such that the constraint $0 \leq \mathrm{N}(\theta) \leq \overline{\mathrm{N}}$ must always hold. The number of layoffs in the unit workforce is given by $(1-\mathrm{N} / \overline{\mathrm{N}})$. Capital is assumed fixed. The firm faces a multiplicatively separable labour services function, L, that takes the form

$$
\mathrm{L}=(\mathrm{H}-\mathrm{m})^{\varepsilon} \mathrm{N}^{\gamma}
$$

where $\mathrm{H}$ is average hours worked per period and $\mathrm{m}$ is set-up time per worker. Further, we assume that $0<\varepsilon<1$ - so that the hours component is concave for $\mathrm{H}>\mathrm{m}$ (with initially increasing and then decreasing returns) - and that $0<\gamma<1$.

Revenue is given by $R=\theta \mathrm{L}$ where $\theta$ is a demand shock. Fixed costs, $Z$, represent the hiring and training cost of long-term workers. The firm's profit is given by

$$
\pi=\mathrm{R}-\mathrm{NW}(\mathrm{H})-\mathrm{NZ}
$$

where $\mathrm{W}(\mathrm{H})$ is the wage schedule. The first order conditions, $\pi_{H}=\pi_{N}=0$, give

$$
\begin{gathered}
\theta \varepsilon\left(\mathrm{H}^{*}-\mathrm{m}\right)^{\varepsilon-1} \mathrm{~N}^{* \gamma}=\mathrm{N}^{*} \mathrm{~W}^{\prime}\left(\mathrm{H}^{*}\right) \\
\theta \gamma\left(\mathrm{H}^{*}-\mathrm{m}\right)^{\varepsilon} \mathrm{N}^{* \gamma-1}=\mathrm{W}\left(\mathrm{H}^{*}\right)+\mathrm{Z}
\end{gathered}
$$

providing that $0 \leq \mathrm{N}(\theta) \leq \overline{\mathrm{N}}$ is non-binding. Dividing (3) by (4) gives

$$
\frac{\varepsilon}{\gamma}=\frac{\left(\mathrm{H}^{*}-\mathrm{m}\right) \mathrm{W}^{\prime}\left(\mathrm{H}^{*}\right)}{\mathrm{W}\left(\mathrm{H}^{*}\right)+\mathrm{Z}},
$$

or the ratio of the returns to hours and workers is equal to the ratio of their respective marginal costs. 
From (5) we find that $\mathrm{H}^{*}$ is independent of $\theta$ in all (layoff) states such that $0 \leq \mathrm{N}(\theta) \leq \overline{\mathrm{N}}$ is non-binding. This result derives from our assumption of a homothetic labour services function. Denote the maximal layoff state by $\bar{\theta}$. There will be non-layoff states $\theta>\bar{\theta}$ for which $\mathrm{N} / \overline{\mathrm{N}}=1$ is binding, $\pi_{N}>0$, and so (4) does not hold. In these non-layoff states, $H^{*}$ will vary directly with $\theta$ by (3).

The wage schedule is given by

$$
\begin{aligned}
\mathrm{W}(\mathrm{H}) & =\mathrm{WH}^{\mathrm{s}}+\mathrm{W}^{\mathrm{o}}\left(\mathrm{H}-\mathrm{H}^{\mathrm{s}}\right) & & \text { for } \mathrm{H}>\mathrm{H}^{\mathrm{s}} \\
& =\mathrm{WH} & & \text { for } \mathrm{H} \leq \mathrm{H}^{\mathrm{s}}
\end{aligned}
$$

where $\mathrm{W}$ is the straight-time wage, $\mathrm{H}^{\mathrm{s}}$ are straight-time hours and $\mathrm{W}^{\circ}$ is the overtime wage. Under Fair Labor Standard Act (FLSA) regulations in the U.S., $\mathrm{H}^{\mathrm{s}}=40$ and $\mathrm{W}^{\circ}=1.5 \mathrm{~W}$.

Substituting (6) into (5) for the case of overtime working, and noting $W^{\prime}(H)=W^{\circ}$, gives $(\gamma-\varepsilon) \mathrm{W}^{\circ} \mathrm{H}^{*}=\varepsilon\left[\mathrm{Z}-\mathrm{H}^{s}\left(\mathrm{~W}^{\mathrm{o}}-\mathrm{W}\right)\right]+\gamma \mathrm{mW} \mathrm{W}^{\circ} 2$ and the condition for overtime working in all states is $\mathrm{H}^{*}>\mathrm{H}^{s}$ or

$$
\varepsilon>\frac{\gamma\left(\mathrm{H}^{\mathrm{s}}-\mathrm{m}\right) \mathrm{W}^{\mathrm{o}}}{\left(\mathrm{Z}+\mathrm{H}^{\mathrm{s}} \mathrm{W}\right)}
$$

As we would expect intuitively, overtime is more likely in layoff states the lower the returns to workers and the lower is the overtime wage (given $\mathrm{H}^{\mathrm{s}}>\mathrm{m}$ ). Also, overtime is likely to be worked if straight-time hours net of set up costs are low. Further, high fixed perworker costs (Z) and costs of straight-time hours (W) are also likely to promote overtime in

\footnotetext{
2 The second-order conditions to the problem in (2) require that $\gamma>\varepsilon$. In this case, we note from this expression that rises in per-worker costs $(\mathrm{Z}$ and $\mathrm{m})$ produce average hours $(\mathrm{H})$ increases, as do reductions in straight-time hours $\left(\mathrm{H}^{\mathrm{s}}\right)$. These are all well known results from workers-hours models given overtime is being worked (e.g. Ehrenberg, 1971) and occur because management substitutes from the extensive margin to the intensive margin to offset the relative rises in stock-related marginal cost.
} 
all states; the former occurs because management discounts high fixed costs with more perworker utilisation.

We have $\mathrm{W}(\mathrm{H})=\mathrm{H}^{*} \mathrm{~W}$ if there is not overtime in layoff states $\left(\mathrm{H} \leq \mathrm{H}^{\mathrm{s}}\right)$ and

$$
(\gamma-\varepsilon) \mathrm{WH}^{*}=\varepsilon(\mathrm{Z})+\gamma \mathrm{mW}
$$

Starting with a single firm, suppose that values of economic variables and parameters are such that overtime is not worked in layoff states. ${ }^{3}$ In these circumstances, if we were to observe the variation of the earnings rate over all demand states and over a long time period, then we would not expect to observe similar cyclical behaviour in its straight-time and overtime components. The straight-time rate may or may not be pro-cyclical, depending on the correlations among the contract-cycle, the characteristics captured by the wage at the point of negotiation, and the business cycle. Providing there were non-layoff states towards cyclical peaks, the overtime component would be pro-cyclical. Overtime earnings would vary directly with the cycle as the higher marginal overtime rates would be switched on towards cyclical peaks when there are no layoffs.

More generally, suppose there is a heterogeneity of firms within an industrial sector that exhibit behaviour in line with the model but with values of economic variables and parameters that result in different employment-hours responses to the cycle. Some firms may employ overtime in all layoff states, some only in non-layoff states, and some not at all. Moreover, some firms may have relatively few values for which $\theta>\bar{\theta}$ while for others this may occur over major phases of the cycle. In general, this would lead to strong expected procyclicality in the overtime component of the earnings rate. At cyclical troughs there would be overtime worked in parts of the economy, as represented by those firms for which (7) holds.

\footnotetext{
${ }^{3}$ One factor which strongly mitigates against the use of overtime in layoff states in a U.S. context is a relatively high value of $\mathrm{W}^{\mathrm{o}}$ in (7).
} 
During expansions, more and more firms will switch from state-independent to statedependent hours and this in turn will cause some to move from straight-time to overtime working.

To the extent that this overtime reaction is observed, we would expect it to impact on the aggregate earnings rate along two routes (see Trejo, 1993 for empirical insights). Suppose that demand changes occur so that we move upwards from the trough of a cycle. First, the earnings rate would rise as a higher proportion of workers work overtime; that is as firms switch at the margin from purely straight-time to overtime working. Second, the earnings rate would rise because the proportion of overtime hours within total average per period hours of existing overtime workers would rise: where hours vary directly with $\theta$ and where overtime schedules are operational, there will be an increase average per-period overtime working. In the following section, we show the relation of these two effects to the overall earnings rate.

\section{Measurement}

In the foregoing model, the workforce is homogeneous in the sense that each worker in the single firm works the same length of hours and receives the same wage and earnings rates. This section tackles problems of dealing with actual data aggregated over all manufacturing firms. There are inevitable definitional differences in that, for example, we may have some workers working only straight-time hours and some straight-time plus overtime. While we adopt a uniform notation throughout, we nevertheless feel that it is clearer to define all variables in this section whether or not they have appeared earlier.

In the U.S., the BLS calculate the earnings rate ${ }^{4}$ (i.e. average hourly earnings), by dividing gross payrolls, by total hours, thus

\footnotetext{
4 See, BLS Handbook of Methods, 1997, Ch. 2 Employment, Hours, and Earnings from the Establishment Survey.
} 


$$
\mathrm{A}_{\mathrm{t}}=\frac{\mathrm{GP}_{\mathrm{t}}}{\mathrm{N}_{\mathrm{t}} \mathrm{H}_{\mathrm{t}}}
$$

where $\mathrm{A}$ is the earnings rate and, as before, $\mathrm{N}$ is total employment and $\mathrm{H}$ is average per-period (paid-for) hours ${ }^{5}$.

In line with the discussion in earlier sections, we can decompose equation (9) by differentiating between overtime workers and workers working only straight-time hours. Under the FLSA, overtime is compensated at a premium rate for hours in excess of 40 per week. In what follows, we make the assumption that overtime workers are compensated for 40 weekly hours at the straight-time rate and then at the mandated premium rate for additional weekly hours. $^{6}$ Accordingly, we may re-express equation (9) in the form

$$
A_{t}=\frac{N_{t} W_{t} H_{t}^{s}+N_{t}^{o} W_{t}\left(40-H_{t}^{s}\right)+N_{t}^{o} W_{t}^{o} V_{t}^{o}}{N_{t} H_{t}^{s}+N_{t}^{o}\left(40-H_{t}^{s}\right)+N_{t}^{o} V_{t}^{o}}
$$

where, $\mathrm{N}^{0} \leq \mathrm{N}$ are the number of employees working overtime, $\mathrm{W}$ and $\mathrm{W}^{\mathrm{o}}$ are the average straight-time and average overtime hourly wage rates, $\mathrm{H}^{s}$ is average weekly straight-time hours of non-overtime workers, $\mathrm{V}^{\circ}=\left(\mathrm{H}^{\circ}-40\right)$ is average overtime hours of overtime workers, and $\mathrm{H}^{\mathrm{o}}$ is average total weekly hours worked by overtime workers.

The numerator of (10) comprises three parts. The first term allows for all $\mathrm{N}$ workers to be paid at the straight-time rate, $\mathrm{W}$ for straight-time hours, $\mathrm{H}^{s}$. These latter hours are averaged over non-overtime workers and we expect $\mathrm{H}^{\mathrm{s}}<40$. Therefore, the second term allows for the fact that $\mathrm{N}^{o}$ overtime workers, assumed to be working 40 straight-time hours, are compensated at $W$ for $\left(40-\mathrm{H}_{s}\right)$ hours. The final term shows that overtime workers are further compensated at the overtime rate, $\mathrm{W}^{0}$ for overtime hours, $\mathrm{V}^{\mathrm{o}}$. The maximum number

\footnotetext{
${ }^{5}$ Detailed descriptions of these variables are given in the Appendix under the Glossary of Definitions.

${ }^{6}$ Actually, there is evidence (Trejo, 1993) that some overtime workers receive the premium before the 40 hour limit. Unfortunately, our data are such that we cannot accommodate this possibility.
} 
of straight time hours and the hourly overtime premium are fixed by legislation. This leaves three variables that relate positively to $\mathrm{A}$; thus, we are interested to distinguish among $\partial \mathrm{A} / \partial \mathrm{W}>0, \partial \mathrm{A} / \partial \mathrm{N}^{o}>0$, and $\partial \mathrm{A} / \partial \mathrm{V}^{o}>0$

However, in the context of estimation, there are two problems with the definition of $A$ in (10): (i) the BLS Establishments Survey does not provide data on $\mathrm{N}^{\mathrm{o}}$ and $\mathrm{V}^{\mathrm{o}}$; (ii) the arithmetic average used to calculate (10) is additive and accordingly cannot be algebraically decomposed into its separate parts. We deal with each of these problems in turn.

The wage rate $\left(\mathrm{W}_{\mathrm{t}}\right.$ in (10)) is approximated by BLS by adjusting average hourly earnings through the elimination of premium pay for overtime at a rate of time and one-half, e.g.

$$
\mathrm{W}_{\mathrm{t}}=\frac{\mathrm{GP}_{\mathrm{t}}}{\mathrm{N}_{\mathrm{t}} \mathrm{H}_{\mathrm{t}}+0.5 \times \mathrm{N}_{\mathrm{t}} \mathrm{H}_{\mathrm{t}}^{\mathrm{o}}} \equiv \frac{\mathrm{GP}_{\mathrm{t}}}{\mathrm{N}_{\mathrm{t}} \mathrm{H}_{\mathrm{t}}^{\mathrm{s}}+1.5 \times \overline{\mathrm{H}}_{\mathrm{t}}^{0}}
$$

where $\overline{\mathrm{H}}^{\mathrm{s}}\left(=\mathrm{H}-\overline{\mathrm{H}}^{0}\right)$ and $\overline{\mathrm{H}}^{\mathrm{o}}$ are, respectively, straight-time and overtime hours averaged over all workers (i.e. overtime and non-overtime workers) ${ }^{7}$. No adjustment is made for other premium payment provisions such as holiday work, late shift work, and premium overtime rates other than those at time and one-half. $\mathrm{W}$ is calculated only for manufacturing industries because data on overtime hours are not calculated in other industries. This is the principal reason why we concentrate our attention on the manufacturing sector.

The BLS Current Population Survey does gather (unpublished) data pertaining to $\mathrm{N}^{\mathrm{o}} .8$ Strictly, $\mathrm{N}^{\mathrm{o}}$ defines the number of workers working in excess of 40 weekly hours and, as mentioned previously, this is how we define overtime workers, e.g.

\footnotetext{
${ }^{7}$ Note that (11) follows the definition given by BLS (Handbook of Methods, 1997, Ch. 2, p 22): "[Average hourly earnings excluding overtime]... are computed by dividing the total production payroll... by the sum of the total production worker hours and one-half of the total overtime hours, which is equivalent to the payroll divided by straight-time hours."

${ }^{8}$ Basic information regarding the Survey and the published data can be found in BLS Handbook (Chapter 1) and the February 1994 issue of the BLS publication called Employment and Earning. There is a complication with
} 


$$
\lambda_{t}=\frac{\mathrm{N}^{\mathrm{o}}}{\mathrm{N}_{\mathrm{t}}}
$$

where $\lambda_{t}$ is the proportion of workers working overtime at time $t$. Then, $H^{s}$ in (10), the number of straight-time hours worked by non overtime workers is given by

$$
\mathrm{H}_{\mathrm{t}}^{\mathrm{s}}=\frac{\overline{\mathrm{H}}_{\mathrm{t}}^{\mathrm{s}}-\lambda \times 40}{(1-\lambda)} \equiv \frac{\mathrm{N} \overline{\mathrm{H}}^{\mathrm{s}}-\left(\mathrm{N}^{\mathrm{o}} \times 40\right)}{\left(\mathrm{N}-\mathrm{N}^{\mathrm{o}}\right)}
$$

Further, $\mathrm{V}^{0}$ in (10) is given by

$$
\mathrm{V}_{\mathrm{t}}^{\mathrm{o}}=\frac{\overline{\mathrm{H}}_{\mathrm{t}}^{\mathrm{o}}}{\lambda_{\mathrm{t}}}
$$

The RHS of (10) decomposes A into the contributions of total and overtime workers. To differentiate explicitly between workers working overtime and those working only straight-time hours while retaining A, we re-express real earnings as a geometric instead of an arithmetic average; thus

$$
\mathrm{A}_{\mathrm{t}}^{*}=\mathrm{E}_{\mathrm{t}}^{\lambda_{t}} \mathrm{~W}_{\mathrm{t}}^{1-\lambda_{t}}
$$

where, $\mathrm{E}$ is average hourly earnings of overtime workers and $\mathrm{W}$ and $\lambda$ are defined in (11) and (12), respectively. Additionally, given FLSA regulations, E can be expressed as

$$
\mathrm{E}_{\mathrm{t}}=\frac{\mathrm{W}_{\mathrm{t}}\left[40+1.5 \times \mathrm{V}_{\mathrm{t}}^{\mathrm{o}}\right]}{40+\mathrm{V}_{\mathrm{t}}^{\mathrm{o}}},
$$

where 1.5 is the mandated U.S. premium and $\mathrm{V}^{\mathrm{o}}$ is defined in (14).

Substituting (16) into (15) and taking logs (shown in lower case) gives

$$
\mathrm{a}_{\mathrm{t}}^{*}=\mathrm{w}_{\mathrm{t}}+\lambda_{\mathrm{t}} \ln \left[\frac{40+1.5 \times \mathrm{V}_{\mathrm{t}}^{\mathrm{o}}}{40+\mathrm{V}_{\mathrm{t}}^{\mathrm{o}}}\right] \text {. }
$$

these data. If, for example, a person worked 40 hours a week at a manufacturing job and then worked another 20 hours in the same week as a clerk in a store, that person would be shown as working 60 hours that week in their manufacturing job. We note that, while dual job holding is generally an important phenomenon, it is clear from the breakdowns of rates of dual job holding provided by Paxson and Sicherman (1996) that manufacturing occupations tend to exhibit below-average rates. 
The intuition behind (17) is simple and relates to expression (10). If $\lambda=0$, all workers receive the average straight-time wage rate and $A^{*}=W$. If $\lambda>0$, then $A^{*}>W$ due to the fact that a proportion of weekly hours for a proportion of workers are compensated at the hourly premium rate. The extent to which $\mathrm{A}^{*}$ diverges from $\mathrm{W}$ relates to our discussion in Sections (1) and (2); it depends on (a) the proportion of overtime to total workers, $\lambda$ and (b) the size of the average premium mark-up, $\ln \left[\frac{40+1.5 \times \mathrm{V}_{\mathrm{t}}^{\mathrm{o}}}{40+\mathrm{V}_{\mathrm{t}}^{\mathrm{o}}}\right]$. Effectively, the mark-up is the weight $(\geq$ 1) which attaches to $\mathrm{W}$ for overtime workers to achieve their average hourly earnings. Obviously, the size of the weight is determined by the number of overtime hours of overtime workers and on the level of the premium. Further note that $A^{*}=A$ when $\lambda=0$ and 1 , otherwise $\mathrm{A}^{*}<\mathrm{A}$. The latter result is a general property pertaining to the relationship between arithmetic and geometric means (Stuart and Ord, 1994, p.45).

Figure 1 below shows the actual relationship between $A$ and $A^{*}$ for U.S. manufacturing over the period 1962-1997. It appears that our alternative measure of A coincides with the official BLS measure and does not alter the inherent underlying variability of the series. However, the clear advantage of employing definition (15) instead of (10) is that, via the appropriate transformation, we will be able to examine the cyclical evolution of its separate components. Following the developments of the previous sections, this should help to shed some light into why time-series estimates of the cylicality of $A$, to date, have not been stable. 
Figure 1: Relationship between A and A*

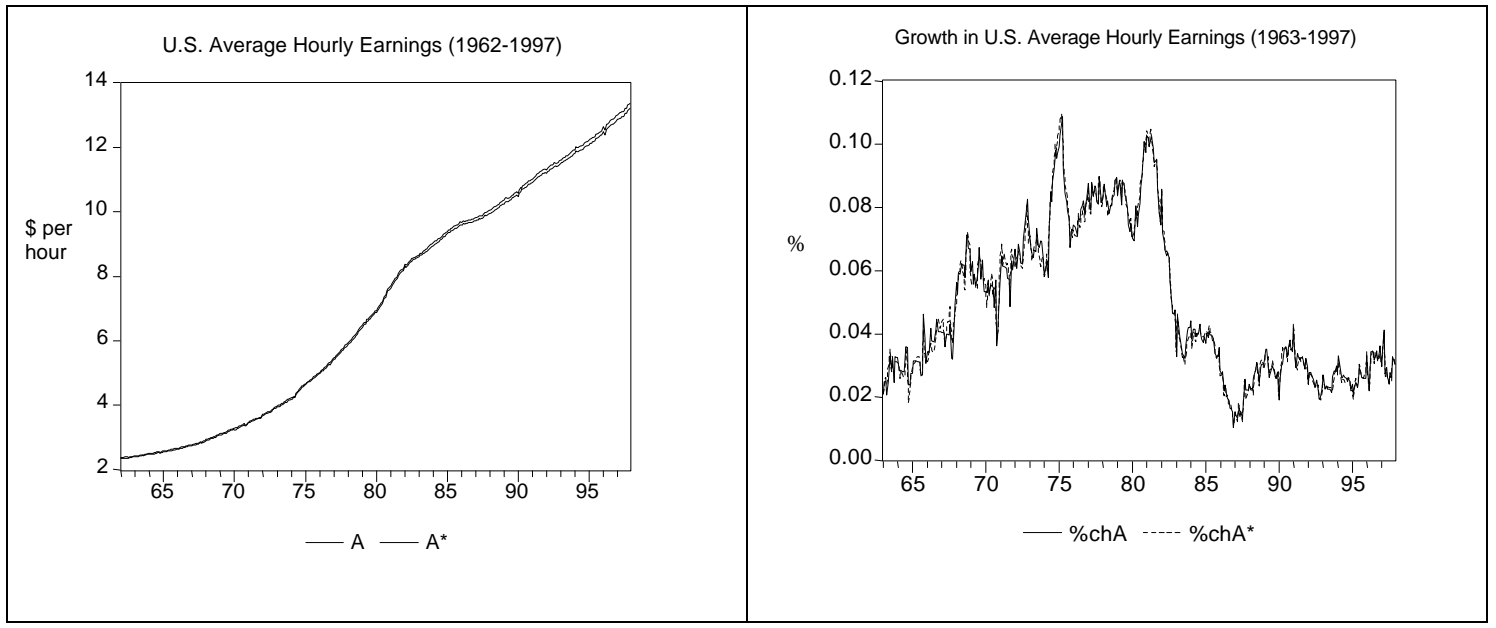

Figure 2: Decompositions of the Earnings Rate

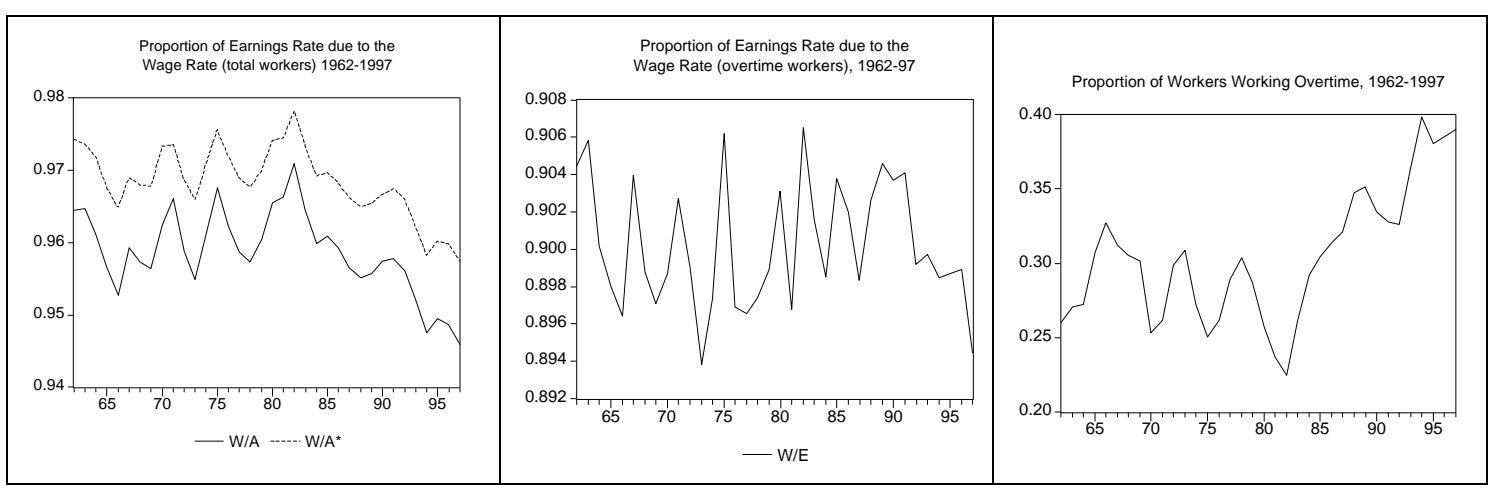

Three aspects of the decomposition of the earnings rate over the period 1962-1997 are presented in Figure 2. First, it shows the share of the wage rate within the earnings rate, averaged over all workers (i.e. overtime and non-overtime). This first graph is constructed with respect to the earnings rate provided by BLS (W/A) and with our own geometric average (W/A*). ${ }^{9}$ Second, it shows the share of the wage rate within the earnings rate for overtime workers only (W/E). Third, it shows the proportion of workers working overtime $(\lambda)$. The first and third graphs, in particular, reflect the growing importance of overtime working after the early 1980s: there is both a fall in the W/A ratio and a marked rise in $\lambda$ from around $22 \%$ to almost $40 \%$ of the male manufacturing workforce.

\footnotetext{
${ }^{9}$ The shapes of the two graphs are identical. W/A lies below W/A* because, as referred to earlier, $\mathrm{A}^{*}<\mathrm{A}$.
} 


\section{Econometric Method and Results}

To describe the cyclical relationship between the earnings rate (and its components) and the business cycle we estimate contemporaneous bivariate correlations using the appropriately filtered data ${ }^{10}$. To this end, we employ U.S. monthly data over the period 1962 to $1997 .{ }^{11}$ One advantage of using correlation coefficients when comparing the cyclical response of variables in different units is that they are bounded in the interval $\{-1$ to 1$\}$. Furthermore, to facilitate an extensive stability analysis we will estimate the correlation coefficients within a regression framework. This is conducted by first normalising each filtered series. Thus, we have

$$
\tilde{Y}_{i}=\frac{F_{j}\left(Y_{i}\right)-\hat{\mu}\left[F_{j}\left(Y_{i}\right)\right]}{\hat{\sigma}\left[F_{j}\left(Y_{i}\right)\right]}, \tilde{X}=\frac{F_{j}(X)-\hat{\mu}\left[F_{j}(X)\right]}{\hat{\sigma}\left[F_{j}(X)\right]}
$$

where $\mathrm{i}=1 . .4$ refers to our variables of interest, as defined in Section 2 , with $1=$ real earnings rate, $2=$ real wage rate, $3=$ proportion of overtime to total workers, and $4=$ average premium mark-up; $\mathrm{X}$ denotes the cycle (based on the index of industrial production); $\mathrm{F}_{\mathrm{j}}$ denotes the deviations from the trend obtained from the various filters $\mathrm{j}=1 . .4$ with $1=$ stochastic difference, 2 = Hodrick-Prescott, 3 = Baxter-King, and 4 = Modified Baxter-King. Second, a bivariate regression is run on using the normalised filtered data, that is

$$
\tilde{Y}_{i}=\tilde{\beta_{i}} \tilde{X}+\varepsilon
$$

where, $\hat{\tilde{\beta}}_{i}=\hat{\beta}_{i} \frac{\hat{\sigma}\left[F_{j}(X)\right]}{\hat{\sigma}\left[F_{j}\left(Y_{i}\right)\right]} \equiv \frac{\hat{\sigma}^{2}\left[F_{j}\left(X Y_{i}\right)\right]}{\hat{\sigma}^{2}\left[F_{j}(X)\right]} \frac{\hat{\sigma}\left[F_{j}(X)\right]}{\hat{\sigma}\left[F_{j}\left(Y_{i}\right)\right]} \equiv \hat{\rho}\left[F_{j}(X) F_{j}\left(Y_{i}\right)\right]$

From (19) it is clear that the estimated value of the normalized slope coefficient is equal to the estimated correlation coefficient in the pre-normalized data.

\footnotetext{
10 Given the well known problems with the Hodrick-Prescott (1980) filter (see for example, Harvey and Jaeger, 1993 and Cogley and Nason, 1995 ), we also employ alternative filters that are designed to minimise the problems associated with the HP-Filter (Baxter and King, 1995 and Woitek, 1998).

11 See the Data Appendix for full details of definitions, sources and methods. Note that application of the Baxter-King and modified Baxter-King bandpass filters requires that we sacrifice 2 years of data from both the beginning and end of the series. Accordingly our results for all filters are reported from 1964 to 1995.
} 
We undertake a forward recursive estimation of (19) from $t_{o}=k+1$ to $T$ as a means of addressing the issue of stability in a systematic fashion. ${ }^{12}$ The vector of standardised ex post prediction errors for $\tilde{Y}_{t}$ when (19) is estimated using t-1 observations is then used to conduct post-sample predictive stability tests based on the Cusum, $\mathrm{W}_{\mathrm{t}}$ and Cusum of Squares, $\mathrm{W}_{\mathrm{t}}^{2}$ (see Brown, et al., 1975) ${ }^{13}$. These tests are designed to test the maintained hypothesis of the time invariance of the regression parameters, i.e. $H_{o}: \tilde{\beta}_{i 1}=\tilde{\beta}_{i 1}=\cdots=\tilde{\beta}_{i T}=\tilde{\beta}$ and $\sigma^{2}\left(\varepsilon_{i 1}\right)=\sigma^{2}\left(\varepsilon_{i 2}\right)=\cdots \sigma^{2}\left(\varepsilon_{i T}\right)=\sigma^{2}(\varepsilon)$ against $H_{1}: \tilde{\beta}_{i t} \neq \tilde{\beta}$ or $\sigma^{2}\left(\varepsilon_{i t}\right) \neq \sigma^{2}(\varepsilon)$ for any $\mathrm{t}=1,2 \ldots \mathrm{T}$. This suggests that, conditional on a constant error variance, failure of $\mathrm{W}_{\mathrm{t}}$ and/or $\mathrm{W}_{\mathrm{t}}^{2}$ is due to coefficient instability only and vice-versa. In the former circumstance, Brown, Durbin and Evans (1974) argue that the Cumsum of Squares, "is a useful complement to the Cumsum test, particularly when the departure from the constancy of the $\beta_{t}{ }^{\prime} s$ is haphazard rather than systematic". However, if the estimated error variance is not constant, then failure of the test can be due either to coefficient and/or variance non- constancy ${ }^{14}$. Based on these considerations, we not only report the $W_{t}$ and $W_{t}^{2}$ but also plots of the recursive estimated coefficients and the error variances. Finally, to obtain some idea of the significance the estimated correlations, we report heteroskedastic recursive t-tests.

\footnotetext{
${ }^{12}$ The results reported below in Figures 3-8 are not altered when the direction of the recursion is reversed and when recursions of varying fixed length are estimated. In the latter case a minimum length of 100 observations was used and a maximum of 200 .

13 Note that the Cusum test, $W_{1}^{+} N(0, t-k)$ and the Cusum of Squares Test $W_{1}^{2} \sim B(0.5(T-t), 0.5(t-k))$. The standard formulas for calculating $W_{t}$ and $W_{t}^{2}$ as well as the significance lines reported in Figures 3-8 can be found in Durbin et al. (op cit.).

14 The findings pertaining to the stability of the regression parameters are not altered when alternative testing procedure are applied, e.g. the recursive F- and t-tests proposed by Spanos (1986, pg. 478) and the two-sided recursive t-test proposed by Harvey and Collier, 1977. To preserve space these results are not presented here but will be made available on request from the authors.
} 
Table 1: Correlation Estimates (1964.1-1995.12)

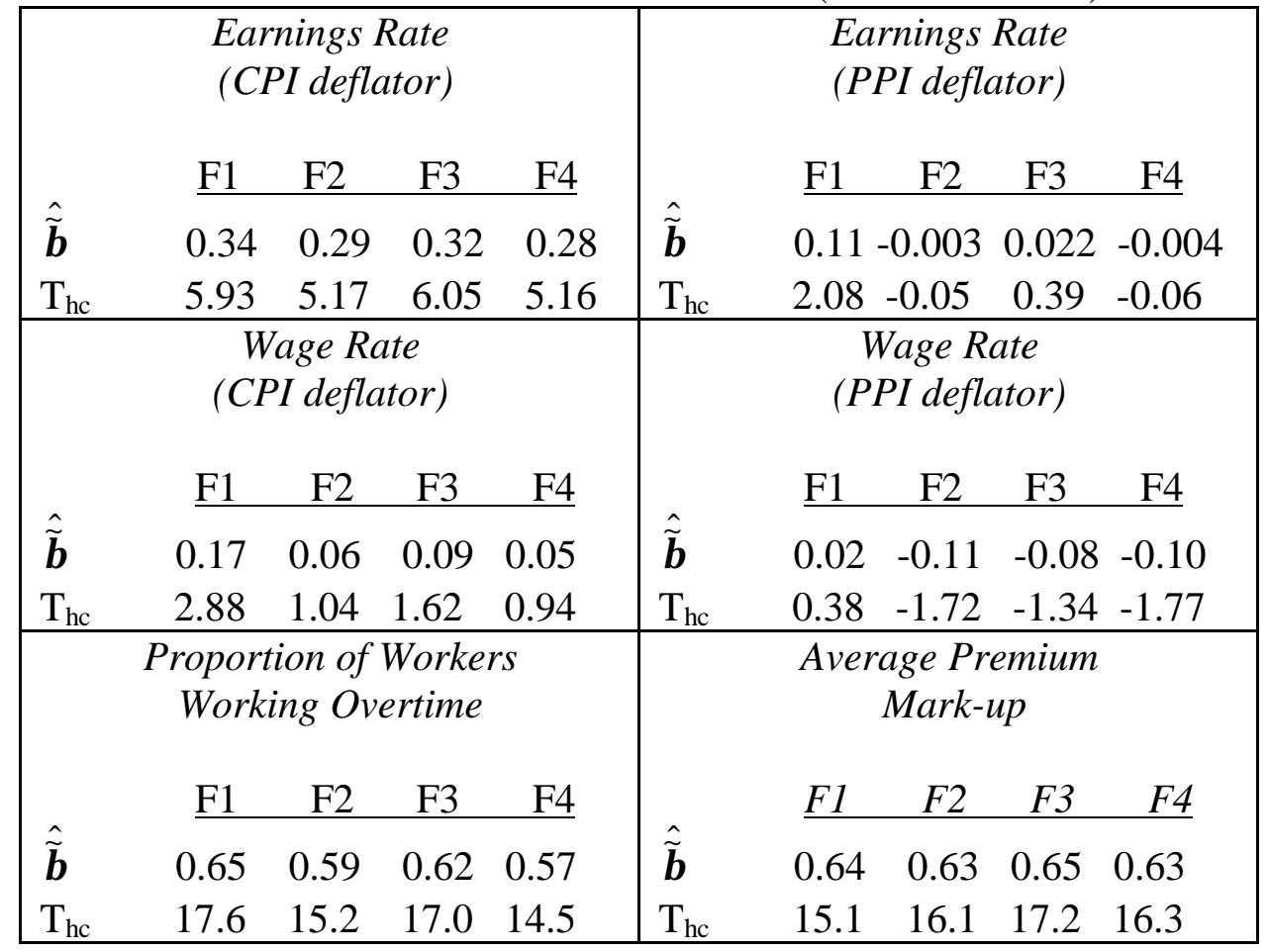

The full sample estimates of (19) are summarized in Table 1. Note that these and subsequent results refer to the four main variables shown in equation (17); these are the earnings rate, the wage rate, the proportion of workers working overtime, and the average premium mark-up. Further, we show two sets of results with respect to the earnings and wage rates; the rates are deflated by the consumer price index (CPI) and by the producer price index (PPI).

As found by Abraham and Haltiwanger (1995) as well as other studies summarised by these authors, Table 1 shows that the earnings and wage rates detrended by the CPI display more procyclicality than using the PPI deflator ${ }^{15}$. In fact the PPI-deflated rates are acyclical. Note, however, with the CPI deflator, the earnings rate is considerably more procycical that the wage rate; in fact, depending on filtering methods, the $\hat{\tilde{\beta}}$ - coefficients on the former are between 2 and (almost) 6 times larger than the latter. The main explanation of these

\footnotetext{
${ }^{15}$ Note that this finding is consistent with the apriori predictions of a number of different stochastic models of the labour market, including the competitive model (see for example Abraham and Haltiwanger, op cit., pp. 1223-24).
} 
observations is that the two remaining components of the earnings rate are highly procyclical. As expected from the discussion in Section 2, both the proportion working overtime and the mark-up are both significantly procyclical, displaying cycle correlations of around 0.61 and 0.64 , respectively. Virtually the whole degree of procyclicality of the earnings rate is accounted for by procyclical adjustments in workers working overtime and in the average overtime worked per worker.

We next turn to a more detailed examination of the results reported in Table 1.

Figures 3-8 provide summaries of $\mathrm{W}_{\mathrm{t}}$ and $\mathrm{W}_{\mathrm{t}}^{2}$ together with complete sets of recursive coefficient estimates of equation (19), t-tests and their error variances. In discussing these, we focus on the period after 1970 to ensure that the recursive estimates have enough initial degrees of freedom. Finally, in contrast to the variable-ordering of equation (17) and Table 1, we start this discussion with reference to the cylicality of the premium mark-up and proportion of workers working overtime $(\lambda)$.

Examination of Figure 3 above indicates that post 1970 the estimated cyclicality coefficient (i.e. correlation) for the mark-up is both stable and significant, as revealed by the recursive t- values. The estimated error variance is quite stable but does display a tendency to drift upwards slightly from 1980 to 1985 . There are virtually no failures on W, across all filtering methods and a relatively low $30 \%$ failure rate on $\mathrm{W}^{2}$. The latter appears to coincide with the increasing error variance in the early 1980's. In some respects the results with respect to the $\lambda$ coefficients in Figure 4 are even stronger. Again there are virtually no 
Figure 3: Recursive Estimates, Average Premium Mark-up (1964.1 to 1995.12)

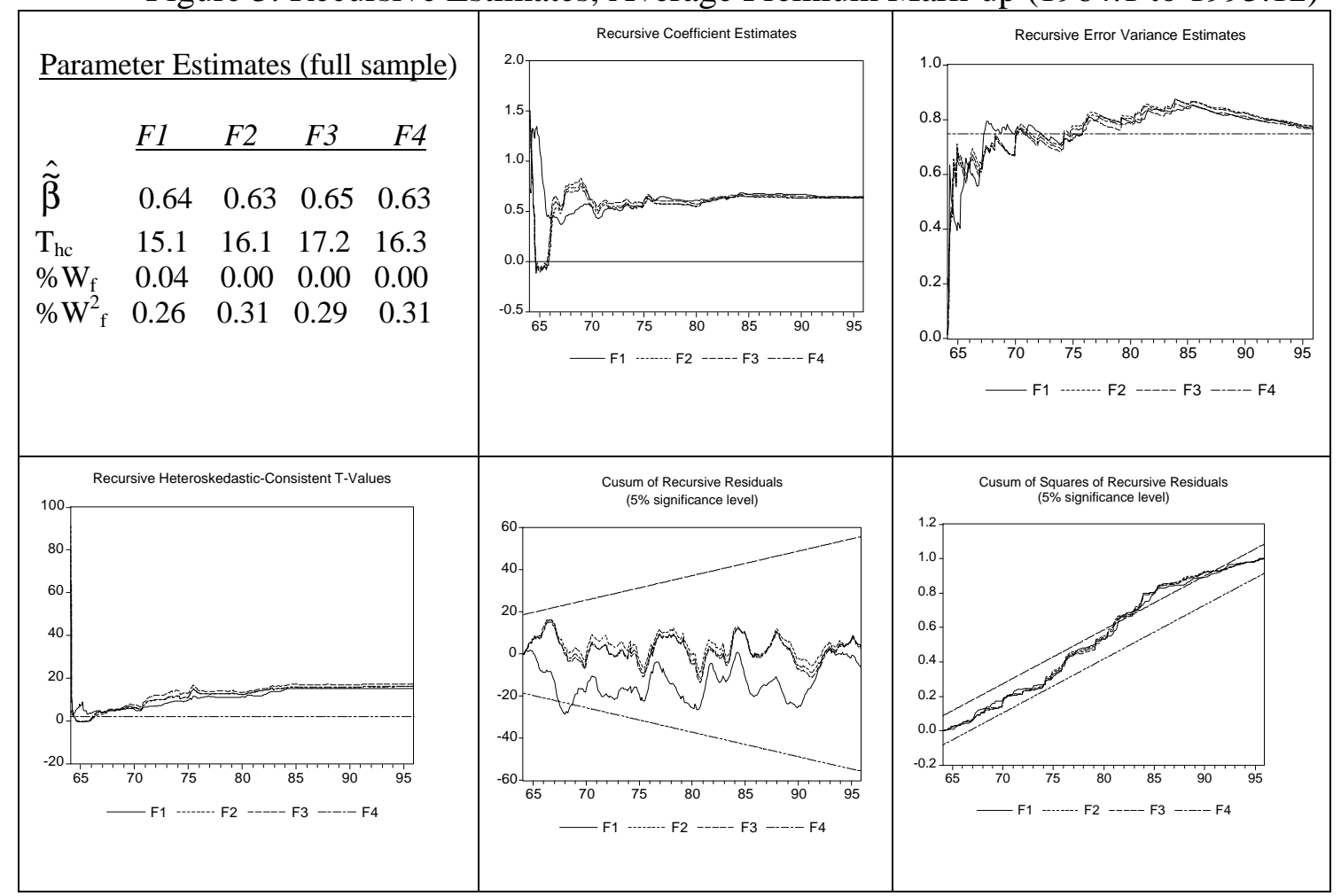

Notes: (i) In Figures 3-8, F1-F4 refers to the difference, Hodrick-Prescott, Baxter-King and modified BaxterKing filters respectively; $\hat{\widetilde{\beta}}$ is the correlation coefficient between the wage and the cycle (iii) $\mathrm{T}_{\text {hc }}$ is based on White's heteroskedastic-consistent standard errors;(iv) $\% \mathrm{~W}_{\mathrm{f}} \& \% \mathrm{~W}_{\mathrm{f}}{ }_{\mathrm{f}}$ refer the proportion of the sample when the CUSUM and CUSUM of Squares test reject the null of equation stability.

failures on $\mathrm{W}$, depending on filtering method and between $13 \%$ and $22 \%$ failure on $\mathrm{W}^{2}$. However, in contrast to the mark-up, there does appear to be a temporary structural break in the estimated correlation between 1970-75. Additionally, the estimated error variance, in contrast to the results in Figure 3, takes slightly longer to stabilise. In summary, the two overtime components appear to be strongly and significantly procyclical and, moreover, they have both displayed relatively high degrees of stability in the face of cycles of varying degrees of severity and representing a wide range of economic events. 
Figure 4: Recursive Estimates, Proportion of Workers Working Overtime (1964.1 to 1995.12$)$

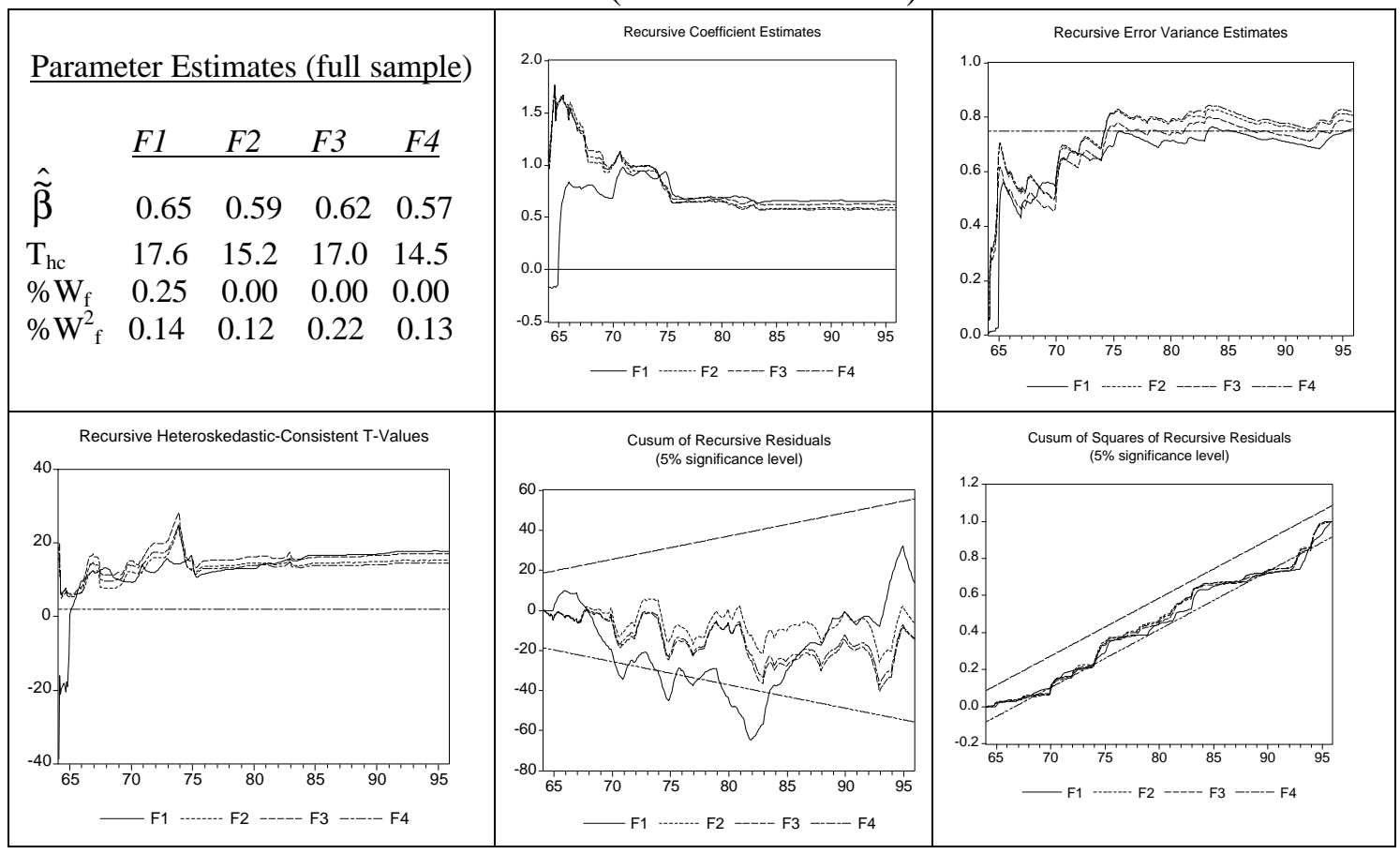

Figure 5: Recursive Estimates, Wage Rate (CPI deflator) (1964.1 to 1995.12)

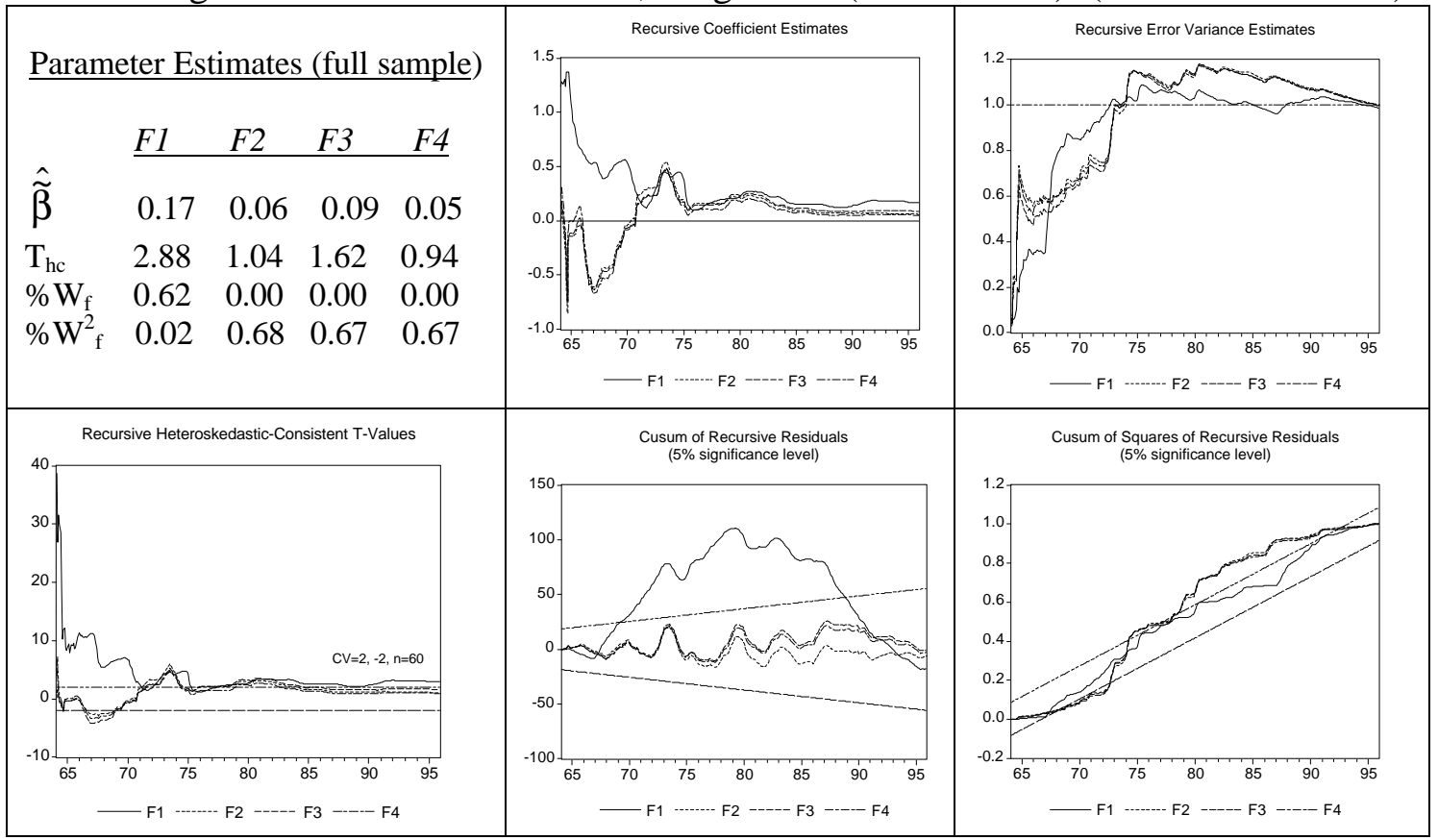


Figure 6: Recursive Estimates, Wage Rate (PPI deflator) (1964.1 to 1995.12)

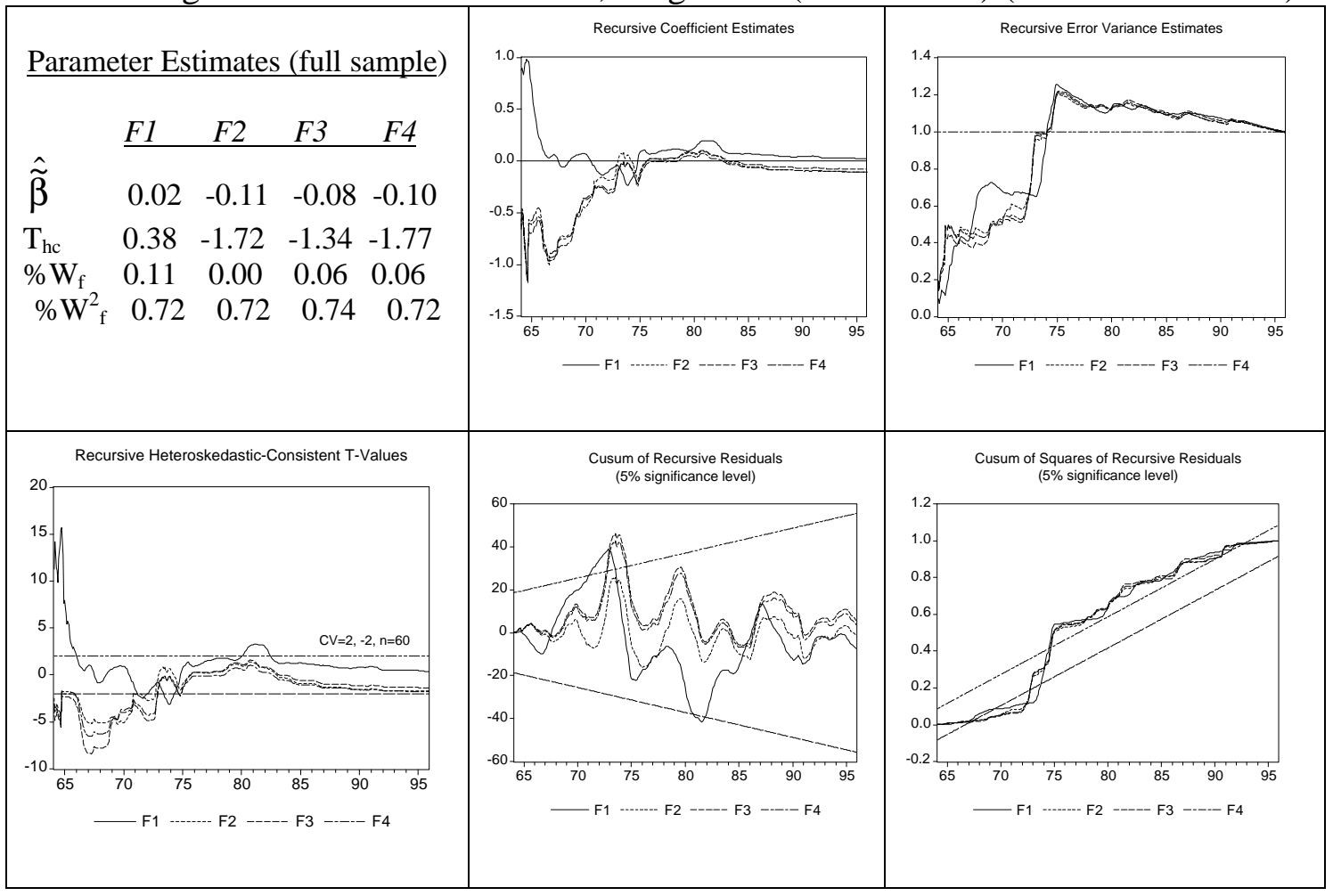

Figure 7: Recursive Estimates, Earnings Rate (CPI deflator) (1964.1 to 1995.12)

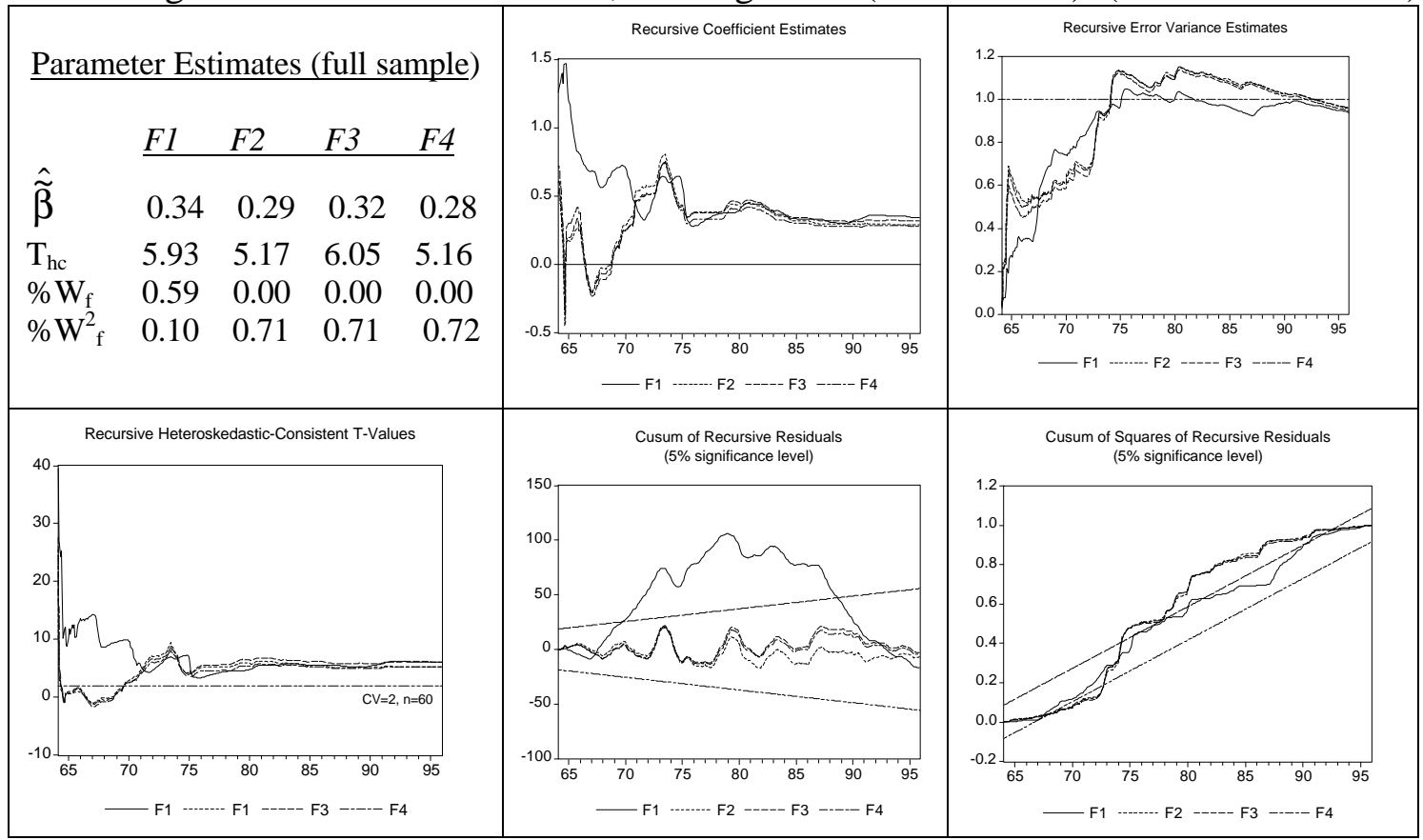


Figure 8: Recursive Estimates, Earnings Rate (PPI deflator) (1964.1 to 1995.12)

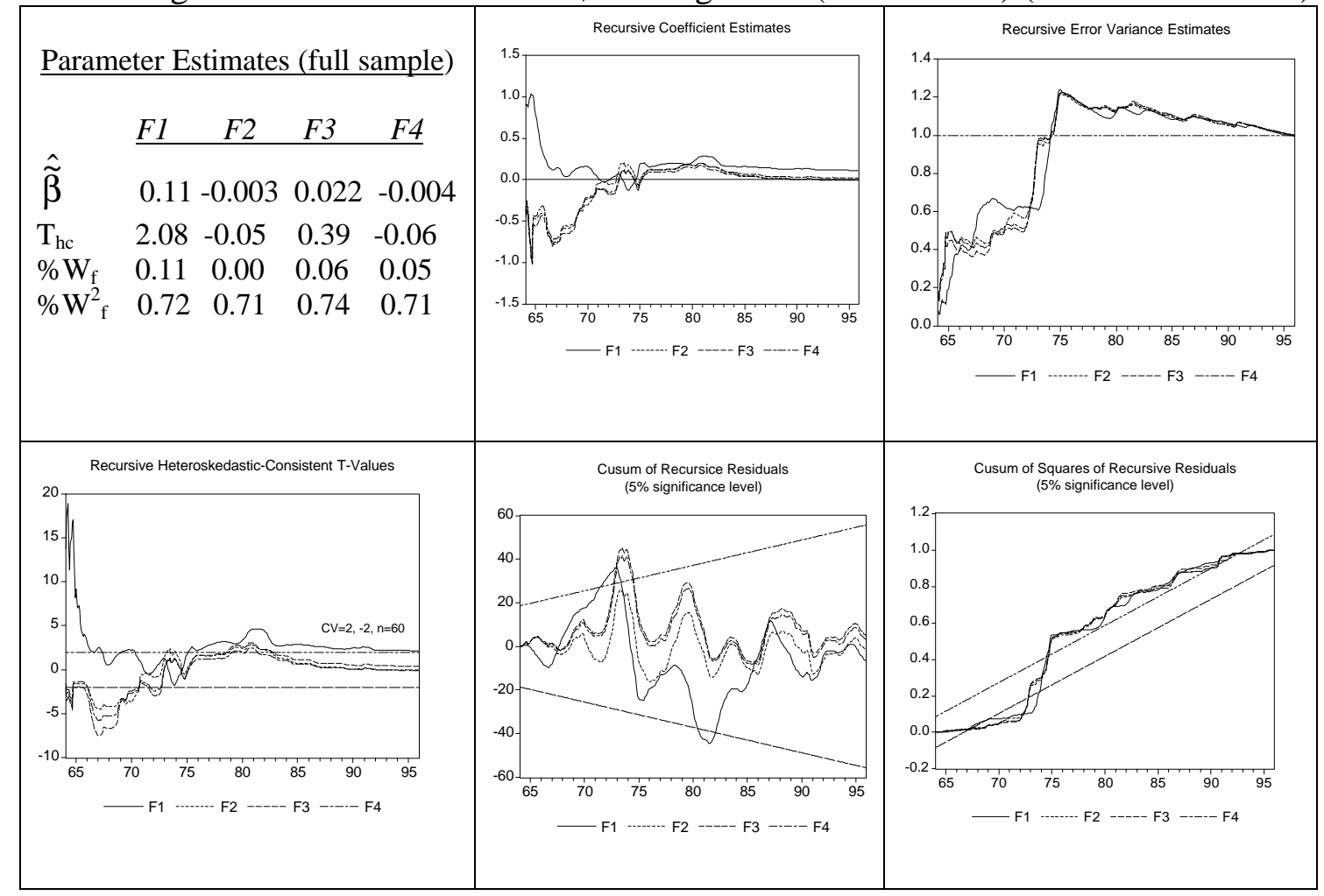

By contrast, the wage rate - which, alongside $\lambda$ and the mark-up, constitutes the third component of the earnings rate - displays highly unstable cylicality coefficients and error variances (see Figures 5 and 6). With the exception of the CPI-deflated wage rate using the difference filter, two thirds of the $\mathrm{W}^{2}$ test reject the null hypothesis of equation stability. Coupled with low positive, or even negative, correlations of the wage rates against the measures of the cycle, our results strongly support the views of others that the wage rate manifests neither a consistent nor a stable cyclical pattern of behaviour.

Of the three components, the wage rate effects dominate the pictures displayed by the earnings rate in Figures 7 and 8 above. Again, there is a general failure to support a null hypothesis of equation stability under the $\mathrm{W}^{2}$ test. $^{16}$ On the basis of the complete set of results, however, it is misleading to conclude that the earnings rate is not flexible or stable.

\footnotetext{
16 We note that, in general, use of the difference filter produces $\mathrm{W}$ and $\mathrm{W}^{2}$ results that differ quite markedly from those derived from the other three filters.
} 
While this is true of the wage rate component, it is certainly not true of its overtime components. It allows for extremely adaptable reactions to economic events on overtime firms' intensive margins.

In Figure 2, we noted the growing importance of overtime in the U.S. after the early 1980s. Given our findings on the procyclicality of the overtime components of the earnings rate, these latter observations almost certainly help to explain why researchers have found a higher tendency to a procyclical earnings rate in post-1970 as opposed to earlier data. ${ }^{17}$

\section{Conclusions}

While overtime working in manufacturing industry is a growing phenomena, affecting about $40 \%$ of U.S. manufacturing workers in our data (see Figure 3), it obviously stops short of providing a universal explanation of how marginal compensation rates may flexibly react to the cycle. Some firms have order books that are not prone to short-term fluctuations in labour inputs: for example, companies involved in large scale engineering projects. In these cases, wage contracts may be dominated by long-term objectives with relative little necessity of gearing compensation to deal with demand shocks. For others, overtime may not be an appropriate form of work scheduling and yet it may still be necessary to respond to demand fluctuations, perhaps through variations in effort, with a concomitant need to accommodate changes in worker opportunity costs. Alternative compensation mechanisms may be adopted in these cases. Incentive payments offer one type of possibility in this respect. Within manufacturing, for example, Ichniowski et al. (1997) show the importance of the use of profit sharing and line incentives ${ }^{18}$ - among other human resource management practices - to

\footnotetext{
${ }^{17}$ See Abraham and Haltiwanger, op cit. for references. We note, however, that these authors find that the wage rate is more procyclical in the later period (see Table 3, p. 1232) and so the explanation here is only a partial one.

${ }^{18}$ Line incentives cover non-traditional pay plans that may be sensitive to the quality and quantity of output.
} 
encourage productivity within U.S. steel finishing plants. ${ }^{19}$ The use of piece-rates, shift premia, holidays in lieu of unscheduled work and, perhaps, certain types of fringe benefits provide other possible devices.

A clear extension of this work is to widen the definition of worker compensation to embrace total labour costs and to find out which other component-parts play the role displayed by the overtime components in this study. The break-down of earnings in (10) can be extended to include other types of workers - e.g. shiftworkers, those on profit-related schemes, workers with certain types of company fringe payments - and relative component cyclicality measured. This might serve to generalise further the key finding here: while the wage rate is not responsive to the cycle, other components of total compensation permit stable pro-cyclical responsiveness by firms in their marginal rates of worker compensation.

\footnotetext{
${ }^{19}$ In fact, a significant rise in profit sharing within labour contracts has been a general feature of the U.S. labour market in recent times (Duca and VanHoose, 1998).
} 


\section{Appendix: Data Definitions, Sources and Methods:}

\section{Glossary of definitions}

Average hourly earnings, A reflect the actual earnings of workers, including premium pay. They differ from wage rates, which are the amounts stipulated for a given unit of work or time. Average hourly earnings do not represent total labour costs per hour for the employer, because they exclude retroactive payments and irregular bonuses, employee non-wage benefits, and the employer's share of payroll taxes. Earnings for those employees not covered under the production worker and non-supervisory categories are not reflected in the estimates.

Gross payrolls, GP are defined as pay before deductions for social security, unemployment insurance, group insurance, withholding tax, salary reduction plans, bonds, and union dues. The payroll figures also include pay for overtime, shift premiums, holidays, vacations, and sick leave paid directly by the employer to the employees for the pay period reported. They exclude bonuses, commissions and other lump-sum payments (unless earned and paid regularly each pay period concerned (e.g. retroactive pay). Tips and the value of free rent, fuel, or other payments in kind are not included.

Total hours, NH during the pay period include all hours worked (including overtime hours), hours for which employment received pay directly from the employer for sick leave, holiday, vacations and other leave. Overtime or other premium pay hours are not converted to straight-time equivalent hours. The concept of total hours differs from scheduled hours or hours worked. The average weekly hours derived from the total hours reflect the effects of such factors as unpaid absenteeism, labor turnover, part-time work, and strikes, as well as fluctuations in work schedules.

Total overtime hours, $\mathrm{N}^{\circ}$ are defined as hours worked for which premiums were paid because they were in excess of the number of hours of either the straight-time workday or workweek. Saturday and Sunday hours (or 6- and $7^{\text {th }}$-day hours) are included as overtime only if overtime premiums were paid. Holiday hours worked as overtime are not included unless they are paid for at more than the straight-time rate. Hours for which only shift differential, hazard, incentive, or similar types of premiums were paid are excluded from overtime hours. Overtime hours data are collected only from establishments in manufacturing industries.

The aggregate manufacturing employment and hours data used in this paper are taken from the Bureau of Labor Statistic (BLS) Establishments (ES) and Current Population Surveys (CPS). The data we employ from the ES is uniformly available on a seasonally adjusted monthly basis starting in 1956. However the data we utilise from the CPS is only available annually from 1962. The monthly observations are obtained by assuming that the annual rate does not change on a monthly basis.

\section{BLS Establishments Survey (National Employment, Hours \& Earnings)}

All employees

Average weekly hours

Average overtime hours

Average hourly earnings

Average hourly earnings excluding overtime
$N$

$H$

$\bar{H}^{o}$

$A$

$W$ 


\section{BLS Current Population Survey (Employment and Earnings)}

Proportion of employees working greater than 40 per week

$\lambda$

\section{Transformations}

Proportion of employees working 40 hours or less per week

Average hourly earnings of overtime workers

$\mathrm{E}=\frac{\mathrm{W}\left[40+1.5 \mathrm{~V}^{\mathrm{o}}\right]}{\mathrm{H}^{\mathrm{o}}}$

Average overtime hours of overtime workers

$\mathrm{V}^{\mathrm{o}}=\frac{\overline{\mathrm{H}}^{\mathrm{o}}}{\lambda}$

Average total hours of overtime workers

$H^{o}\left(=V^{\circ}+40\right)$

Alternative Measure of Average hourly earning

$\mathrm{A}^{*}=\mathrm{E}^{\lambda} \mathrm{W}^{1-\lambda}$

The following production and price data is uniformly available on a seasonally adjusted monthly basis starting in 1949 .

Industrial Production Index, Manufacturing $\quad Y$

Source: Federal Reserve Board (FRB)

Consumer Price Index for All Urban Consumers, CPI-U-X1 ${ }^{20} \quad P^{c}$

Source: BLS

Producer Price Index, All Commodities

$P^{p}$

Source: BLS

20 The CPI-U-X1 is a BLS retrospectively calculated estimate of how the all items index would have moved (from 1967 to 1982) had the CPI been calculated using the flow of services approach to shelter. Prior to 1967 we use the official series reported by BLS. In December 1982 the production CPI began to use the flow of services approach. Hence as in other studies of wages (see for example Abraham and Haltiwanger (1995) we are employ the CPI which is most consistent with the series currently reported by BLS. We would like to thank the BLS for providing the unpublished 1967-82 data. 


\section{References}

Abraham, K.G. and J.C. Haltiwanger (1995), Real wages and the business cycle, Journal of Economic Literature, 33, 1215-64.

Blanchard, O.J. and S. Fischer (1989), Lectures on Macroeconomics, Cambridge, MA: MIT Press.

BLS Handbook of Methods, 1997, Bureau of Labor Statistics, U.S. Department of Labor.

Brown, R., Durbin, J., and J. Evans, 1975, Techniques for testing the constancy of regression relationships over time, Journal of the Royal Statistical Society, Series B, 37, 149-192.

Cogley, T. and J. Nason, 1995, Effects of the Hodrick-Prescott filter on trend and difference stationary time series: Implications for business cycle research, Journal of Economic Dynamics and Control, 19, 253-278.

Duca, J.V. and D.D. VanHoose, 1998, Goods-market competition and profit sharing: a multisector macro approach, Journal of Economics and Business, 50, 525-34

Ehrenberg, R.G., 1971, Fringe benefits and overtime behavior, Lexington, MA: D C Heath

FitzRoy, F.R. and R.A. Hart, 1985, Hours, layoffs and unemployment insurance funding: theory and practice in an international perspective, Economic Journal, 95, 700-13.

Hall R.E. and D.M. Lilien, 1979, Efficient wage bargains under uncertain supply and demand, American Economic Review, 69, 868-79.

Harvey, A. and A. Jaeger, 1994, Detrending, stylised facts and the business cycle, Journal of Econometrics, 8, 231-247.

Harvey, A. and P. Collier, 1977, Testing for functional misspecification in regression analysis, Journal of Econometrics, 6, 103-119.

Hodrick, R. and E. Prescott, 1980, Postwar U.S. business cycles: An empirical investigation, Discussion Paper No. 451, Carnegie-Mellon University.

Ichniowski, C., K.Shaw and G.Prennushi, 1997, The effects of human resource management practices on productivity: a study of steel finishing lines, American Economic Review, 87, 291-313.

Paxson, C.H. amd N. Sicherman, 1996, The dynamics of dual job holding and job mobility, Journal of Labor Economics, 14, 357 - 93.

Spanos, A., 1986, Statistical Foundations of Econometric Modelling, Cambridge University Press, Cambridge.

Stuart, A. and J. Ord, 1994, Kendall's Advanced Theory of Statistics: Distribution Theory (6 ${ }^{\text {th }}$ ed.) Edward Arnold, London.

Trejo, S.J., 1993, Overtime pay, overtime hours, and labor unions, Journal of Labor Economics, 11, 253-78.

Woitek, U., 1998, A Note on the Baxter-King Filter, University of Glasgow Discussion Paper No. 9813. 